East African Medical Joumal Vol. 84 No. 1 January 2007

QUALITY OF RECORD KEEPING IN THE INTRAPARTUM PERIOD AT THE PROVINCIAL GENERAL HOSPITAL, KAKAMEGA, KENYA

E.B. Wamwana MD, MMed, Specialist Obstetrician and Gynaecologist, Pumwani Maternity Hospital, Nairobi, P.O. Box 42849-00100, Nairobi, Kenya, P.M. Ndavi, MBChB, MMed, MSc. Epid, DLSHTM, FHBR, Senior Lecturer, Department of Obstetrics and Gynaecology, College of Health Sciences, University of Nairobi, P.O. Box 19676-00202, Nairobi, Kenya, P.B. Gichangi, BSc. (Anatomy), MMed, PhD, Senior Lecturer, Department of Human Anatomy/Obstetrics and Gynaecology, College of Health Sciences, University of Nairobi, P.O. Box 19676-00202, Nairobi, Kenya, J.G. Karanja, MBChB, MMed, Associate Professor, Department of Obstetrics and Gynaecology, College of Health Sciences, University of Nairobi, P.O. Box 19676-00202, Nairobi, Kenya, E.G. Muia MBChB, MPH, DrPH, Programme Associate, Population Council, G.W. Jaldesa, MBChB, MMed, MSc. Rep. Health, Specialist Obstetrician and Gynaecologist, Kenyatta National Hospital, P.O. Box 20723-00202, Nairobi, Kenya

Request for reprints to:Dr. P.M. Ndavi, Department of Obstetrics and Gynaecology, College of Health Sciences, University of Nairobi, P.O. Box 19676-00202, Nairobi, Kenya

\title{
QUALITY OF RECORD KEEPING IN THE INTRAPARTUM PERIOD AT THE PROVINCIAL GENERAL HOSPITAL, KAKAMEGA, KENYA
}

\author{
E.B. WAMWANA, P.M. NDAVI, P.B. GICHANGI, J.G. KARANJA, E.G.MUIA and G.W. JALDESA
}

\begin{abstract}
Objective: To assess the quality of recording critical events in the intrapartum period in Kakamega Provincial General Hospital (PGHK).

Design: Retrospective comparative study.

Setting: Provincial General Hospital, Kakamega, the referral hospital for Western Province; Kenya.

Participants: Two hundred women admitted at the labour ward during the six-month period between $1^{\text {st }}$ September 2000 and $28^{\text {th }}$ February 2001 were compared to two hundred women admitted between 1st July 2001 and 31st December 2001.

Intervention: The Safe Motherhood Demonstration Project (SMDP) was introduced in four districts of Western Province, Kenya, in which PGHK is located. It included on job training in Safe Motherhood which emphasised, among others, collection and utilisation of maternal health care services data.

Main outcome measures: Comprehensiveness of recording of biodata, history taking and examination findings were assessed for women in labour before and during the implementation of the SMDP. The proportion of cases in labour managed by use of partograph and its appropriate use were also determined.

Results: Retrieval rate of patients' notes was $86.9 \%$ and $89.6 \%$ before and during SMDP respectively. Information on sociodemographic characteristics, history taking, general and obstetric examination had a near universal recording in both groups but data on alcohol consumption, smoking, menarche, previous pregnancies and contraceptive use was poorly recorded. There was a significant improvement in recording of diagnosis and plan of management during the SMDP $(p=0.037)$. The partograph was used in only $11 \%$ of patients before SMDP as compared to $85 \%$ during SMDP $(p=0.000)$. Record on foetal condition and progress of labour were significantly improved during the SMDP $(p=0.000)$. Records on summary of labour likewise significantly improved during the SMDP ( $p=0.02)$. Conclusion: The quality of record keeping in the intrapartum period at the PGHK greatly improved during the implementation of the SMDP. It would be worthwhile to assess the sustainability of quality of intrapartum records and care a year or so after the SMDP ended.
\end{abstract}




\section{INTRODUCTION}

Medical Records in the intrapartum period include maternity admission books, patients case notes, the partograph, delivery books and operating theatre register. They play an important role in the management of patients and are used to obtain biodata, clinical features, investigations ordered and their results, diagnosis and treatment. Properly kept and utilised medical records, especially the partograph, in the intrapartum period have been shown, worldwide, to improve the quality of care and outcome of labour and delivery and minimise the Caesarian section rate (1-3). In Kenya, this was demonstrated by Wasike (4) who evaluated the impact of the Ministry of Health partograph on the active management of labour at Moi Teaching and Referral Hospital Eldoret. Wanjara (5) also showed improved outcome of labour when managed using the partograph. In the baseline survey of December 2000 in Western Province as part of the Safe Motherhood Demonstration Project (6) (SMDP) on approaches for providing quality maternal care in Kenya, 243 case records were examined. Standard partograph was used in $23 \%$ of normal deliveries, delivery summaries in $72 \%$ and other records, mainly admission notes, used in $5 \%$ of the cases.

The $W H O(1)$ universal partograph representing synthesised and simplified compromise of the best features of several partographs is an ideal tool in the management of labour both at health centre level as a criterion for referral, and at hospital level as a criterion for active management of labour or operative intervention (1-3).

It is basically a graphic representation of events of labour plotted against time in hours. It consists of three components: a) the foetal condition with emphasis on foetal heart rate, status of the liquor amnii, and degree of moulding; $b$ ) the progress of labour monitored using the cervical dilatation, uterine contractions and the descent of the presenting part and finally c) the maternal condition which include the vital signs-blood pressure, pulse, temperature and respiration- along with determination of the urine volume and analysis for proteinuria, glycosuria and ketonuria. These are the components used in monitoring vital events during labour. In increasing the quality or regularity of the critical observations of the foetus, the mother and progress of labour, it has been shown to improve the outcome of labour and delivery in several studies $(1,4,5)$.

There is scanty literature on the other records apart from the partograph in the intrapartum period. Maclnerney et al (7), in an audit of care given to mothers in a maternity unit of a large academic hospital found that past medical history was only documented in $54 \%$ of the cases admitted. Past obstetric history was documented in close to $70 \%$ in comparison with the present antenatal history, which was only reflected in $12 \%$ of the records. Foetal heart rate was recorded in only $79 \%$ of the cases. Comprehensive vaginal examination findings were recorded in only $18 \%$ with instances where recording reflected inadequate knowledge of the procedure.

The objective of this study was to determine the quality of recording vital events during the intrapartum period at the Provincial General Hospital in Kakamega. This quality would provide an indication of the quality of care given to mothers in the intrapartum period in this hospital.

\section{MATERIALS AND METHODS}

Study design: This was a retrospective comparative study in which two groups of women were studied in the intrapartum period. The first group of 200 randomly sampled patients' notes included women who delivered between $1^{\text {st }}$ September 2000 and $28^{\text {th }}$ February 2001 before the implementation of the SMDP. This was compared with the second group, which included 200 women whose case notes were randomly sampled for the period between $1^{\text {st }}$ July 2001 and $31^{\text {st }}$ December 2001 during the early phase of the implementation of the SMDP. Every tenth file was picked for the study as the records were retrieved chronologically. The data was collected over a period of one month between $1^{\text {st }}$ March 2003 and $31^{\text {st }}$ March 2003.

Study area: The study was carried out in Kakamega Provincial Hospital situated in Kakamega town, which hosts the administrative headquarters of Western Province with a population of 3,358,776 out of whom 770,771 are women in the reproductive age (8). The Provincial General Hospital is a primary health facility for the town population while providing specialised medical services for referred cases in the entire province. The departments include Obstetrics/Gynaecology. Obstetrics has an 
operating theatre for both elective and emergency cases.

Sample size: Using EPINFO soft ware, the sample size was calculated thus: Percent use of partograph in management of labour before introduction of SMDP(28\%) Percent use of partograph in management of labour during introduction of SMDP-(42\%) Confidence level of $95 \%$, that is, the probability that if the two samples differ, this reflects a true difference in the two populations. Power of $80 \%$, that is, the probability that if the two populations differ, the two samples will show a significant difference.

Sample size before introduction of SMDP $=195$ rounded up to 200.

Sample size after introduction of SMDP $=195$ rounded up to 200 .

Inclusion criteria: All records of patients who had been admitted to labour ward in the latent or active phase.

Exclusion criteria: Pregnancy gestation less than 34 weeks, patients delivered by Caesarian section on an elective basis, patients admitted when in second stage of labour and cases that required emergency caesarian section on admission.

Study procedure: A nurse-midwife (a Kenya registered community health nurse KRCHN) and a medical records officer were recruited and trained for the study during the pre-testing. Working with the delivery records and operating theatre register, which provided the sampling frame, 200 case files were picked chronologically by sampling every tenth eligible case between $1^{\text {st }}$ September 2000 and $28^{\text {th }}$ February 2001. The second group included 200 cases recorded from $1^{\text {st }}$ July 2001 to $31^{\text {st }}$ December 2001 after the in-service seminar of service providers in the month of May and June 2001. Data was entered in a structured pre-coded questionnaire. Computer analysis included descriptive statistics and appropriate tests applied to determine significant differences in the quality of recording vital information during the intra-partum period.

Ethical consideration: Permission to carry out the study was obtained from the Ministry of Health through the Provincial General Hospital Kakamega administration and the Provincial Medical Officer
(PMO). The records were coded and patients' names were not used. The proposal was submitted tor and approval granted by, the Ethical and Research Committee of Kenyatta National Hospital.

\section{RESULTS}

The total number of eligible cases recorded in the delivery book before safe motherhood demonstration project (SMDP) was 2310 while the total number of corresponding files retrieved from the central records was 2009. Retrieval rate was $87 \%$. During the SMDP the retrieval rate was $90 \%$. At least $96 \%$ of case files had all demographic data recorded in both groups except religion where only $5 \%$ and $4 \%$ were recorded respectively.

Table 1

Distribution of recording of sociodemographic characteristics

\begin{tabular}{|c|c|c|}
\hline \multirow[t]{2}{*}{ Variable } & \multicolumn{2}{|c|}{ Number of files with records } \\
\hline & $\begin{array}{c}\text { Before SMDP } \\
(\%)\end{array}$ & $\begin{array}{c}\text { During SMDP } \\
(\%)\end{array}$ \\
\hline Name & 100 & 100 \\
\hline Age & 100 & 100 \\
\hline Inpatient number & 98 & 100 \\
\hline Level of education & 96 & 99 \\
\hline Residence & 97 & 99 \\
\hline Religion & 5 & 4 \\
\hline
\end{tabular}

As shown in Table 2, data on main complaints, history of present illness and past medical history were well recorded both before and during the SMDP intervention with over $95 \%$ of the records containing these parameters. There was however significant improvement in data recorded on family and social history in $100 \%$ of the records. Data on alcohol consumption and smoking improved to $72 \%$ and $62 \%$ respectively during the intervention period as compared to data recording before SMDP$58 \%$ and $55 \%$ respectively $(p=0.01)$. Information on last normal menstrual period, expected date of delivery, gestation by dates and parity were recorded with at least $97 \%$ frequency during the two study periods. Recording of antenatal care and antenatal tests during the two periods remained at about $80 \%$. The recording of menarche, history of previous pregnancy and contraceptive use did not 
Table 2

Distribution of recorded elements of history taken

\begin{tabular}{|c|c|c|c|c|}
\hline \multirow[t]{2}{*}{ Variable } & \multicolumn{4}{|c|}{ Number of files with variables recorded } \\
\hline & $\begin{array}{c}\text { Before SMDP } \\
\qquad(\mathrm{n}=200) \\
(\%)\end{array}$ & $\begin{array}{l}\text { During SMDP } \\
\qquad \begin{array}{c}(n=200) \\
(\%)\end{array}\end{array}$ & $x^{2}(\mathrm{DF})$ & P-value \\
\hline \multicolumn{5}{|l|}{ Complaints } \\
\hline Main complaints & 100 & 100 & & \\
\hline History of present illness & 96 & 96 & & \\
\hline Past medical history & 99 & 100 & $0.01(2)$ & 0.284 \\
\hline \multicolumn{5}{|l|}{ Family and social history } \\
\hline Marital status & 89 & 100 & & \\
\hline Employment & 83 & 100 & & \\
\hline Chronic illness in the family & 90 & 100 & & \\
\hline History of twin pregnancy & 87 & 100 & & \\
\hline Alcohol consumption & 58 & 72 & $7.45(1)$ & 0.006 \\
\hline Smoking & 55 & 62 & $1.73(1)$ & 0.19 \\
\hline \multicolumn{5}{|l|}{ Obstetrics/gynaecology history / investigations } \\
\hline Menarche and characteristics of menstrual cycle & 53 & 62 & & \\
\hline Parity & 97 & 99 & & \\
\hline If parous, history of previous pregnancy(ies) & 45 & 50 & & \\
\hline Contraceptive use & 42 & 47 & & \\
\hline Last normal menstrual period & 100 & 100 & & \\
\hline Expected date of delivery & 100 & 100 & & \\
\hline Gestation by dates & 100 & 100 & & \\
\hline Antenatal clinic attendance & 88 & 90 & & \\
\hline Antenatal profile (Hb. VDRL, blood group/rhesus) & 76 & 78 & & \\
\hline
\end{tabular}

change significantly from the low level before the SMDP. There was an almost $100 \%$ data recording of findings on general and obstetric examinations in both groups except the recording of presentation where $91 \%$ recorded before SMDP as opposed to $100 \%$ recorded during SMDP (Table 3 ).

As shown in Table 4, diagnosis and plan of management were recorded in $86 \%$ and $84 \%$ in the first group compared to $100 \%$ in the second group which was a significant improvement ( $p$ $<0.05$ ). Partograph as an intrapartum record was used in only $11 \%$ of the first group as compared to the second group where it was used in $85 \%$ of the cases $(p=0.000)$. In Table 5 , the 22 case notes in the first group in which the partograph was used were compared with 171 case notes in the group during SMDP where the partograph was used. This was undertaken in order to elicit the appropriateness of use of partograph in both groups. The foetal condition and progress of labour data records significantly improved during the SMDP with $100 \%$ recording except for moulding and caput $76 \%$ and
$77 \%$ respectively $(p=0.000)$. Recording of maternal blood pressure, pulse, temperature, and respiration showed significant increase from less than $76 \%$ to over $90 \%$ during the SMDP intervention ( $p<0.004)$. However, the three important parameters assessed during urinalysis (ketonuria 25 vs $43 ; \mathrm{p}=0.0002$, proteinuria 30 vs $45 ; \mathrm{p}=0.002$, urine volume 34 vs $60 ; \mathrm{p}=0.0000$ ) though improved in the intrapartum period remained inadequately recorded during the implementation of the SMDP.

Table 6 shows marked improvement in recording duration of labour in the second group especially duration of 1st stage of labour where there was $87 \%$ recording in the first group compared to $96 \%$ in the second group ( $p=0.02$ ). There was a lower recording of duration of 2 nd and 3rd stages of lab our in both groups (71\% - before; $78 \%$ - during). Important parameters during the fourth stage of labour were also more comprehensively recorded in the second group with the greatest improvement in blood loss assessmnent (77\% before; $96 \%$ - during; $\mathrm{p}=0.02$ ). The lowest recorded parameter here was 
Table 3

Distribution of examination recording

\begin{tabular}{lcc}
\hline Variable & $\begin{array}{c}\text { Number of files with variables recorded } \\
\text { Before SMDP } \\
(\mathrm{n}=200)(\%)\end{array}$ & $\begin{array}{c}\text { During SMDP } \\
(\mathrm{n}=200)(\%)\end{array}$ \\
\hline Pallor & 100 & 100 \\
Oedema & 100 & 100 \\
Jaundice & 99 & 100 \\
Fundal height & 100 & 100 \\
Lie & 100 & 100 \\
Presentation & 91 & 100 \\
\hline
\end{tabular}

Table 4

Distribution of recording of diagnosis, plan of management and partograph use

\begin{tabular}{lccc}
\hline Variable & \multicolumn{3}{c}{ Number of files with variables recorded } \\
& $\begin{array}{c}\text { Before SMDP } \\
(\mathrm{n}=200)(\%)\end{array}$ & $\begin{array}{c}\text { During SMDP } \\
(\mathrm{n}=200)(\%)\end{array}$ & $\begin{array}{c}\text { P-value } \\
\end{array}$ \\
\hline Diagnosis & 86 & 100 & 0.037 \\
Plan of Management & 84 & 100 & $<0.05$ \\
Partograph use & 11 & 85 & 0.000 \\
\hline
\end{tabular}

Table 5

Distribution of recording of foetal condition and progress of labour

\begin{tabular}{lccc}
\hline Variable & $\begin{array}{c}\text { Number of files with variables recorded } \\
\text { Before SMDP } \\
(\mathrm{n}=22)(\%)\end{array}$ & $\begin{array}{c}\text { During SMDP } \\
(\mathrm{n}=170)(\%)\end{array}$ & P-value \\
\hline Foetal condition & & & \\
$\quad$ Foetal heart rate & 100 & 100 & 0.00 \\
Status of membranes and liquor & 86 & 700 & 0.51 \\
Degree of moulding & 82 & 77 & 0.64 \\
Caput & 74 & 100 & 0.0000 \\
Progress of labour parameters & & 100 & 0.0000 \\
Cervical dilatation & 86 & 100 & 0.0001 \\
Descent of presenting part & 86 & & \\
Uterine contractions & 91 & & \\
\hline
\end{tabular}

the status of cond (67\% -before; $76 \%$ during; $\mathrm{p}=0.02$ ). Recording about the newborn was almost $100 \%$ in both groups. Information on the mode of delivery was available in $100 \%$ of the records during the two periods. About $74 \%$ of the mothers in the first group had spontaneous vertex delivery in comparison with the second group where the number increased to $78.5 \%$. The rate of vacuum extraction was the same while the number of women delivered by Caesarean section in first group (24.3\%) was more than in the second group (20\%).
In Table 7, there was $100 \%$ record on duration of labour and Apgar score before and during the SMDP. Improvements in data storage during the implementation of the SMDP improved overall. The patient's intrapartum notes were recorded $100 \%$ in both groups. Data recording and keeping of other parameters i.e. treatment sheet, observation chart antenatal records were more effectively kept in the second group ( $88 \%-99.5 \%$ ) compared to $48 \%$ - $94 \%$ in the first group. 
Table 6

Percent recording of summary of labour

\begin{tabular}{lccc}
\hline Variable & $\begin{array}{c}\text { Number of files with variables recorded } \\
\text { Before SMDP } \\
(\mathbf{n}=\mathbf{2 0 0 )}(\%)\end{array}$ & $\begin{array}{c}\text { During SMDP } \\
(\mathbf{n}=\mathbf{2 0 0})(\%)\end{array}$ & P-value \\
\hline $\begin{array}{l}\text { Duration of labour } \\
\text { First stage }\end{array}$ & 75 & 96 & 0.001 \\
Second stage & 72 & 78 & 0.13 \\
Third stage & 71 & 78 & 0.11 \\
Fourth stage parameters & & & \\
Blood pressure measurement & 77 & 96 & 0.000 \\
Status of placenta & 73 & 76 & 0.6 \\
Syntocinon/Ergometrine & 78 & 90 & 0.003 \\
Status of membranes & 75 & 85 & 0.013 \\
Status of the cord & 67 & 76 & 0.06 \\
New born & & & \\
Status & 99 & 100 & \\
Sex & 100 & 100 & \\
Birth weight & 100 & 100 & \\
\hline
\end{tabular}

Table 7

Percent recording of duration of labour, Apgar score and comprehensiveness of storage

\begin{tabular}{lccc}
\hline Variable & $\begin{array}{c}\text { Number of files with variables recorded } \\
\text { Before SMDP } \\
(\mathrm{n}=200)(\%)\end{array}$ & $\begin{array}{c}\text { During SMDP } \\
(\mathrm{n}=200)(\%)\end{array}$ & P-value \\
\hline Duration of labour & 100 & 100 & \\
Apgar score & 100 & 100 & \\
Comprehensiveness of storage & & & \\
$\quad$ Patients' inpatient notes & 100 & 100 & 0.0000 \\
Treatment sheet & 48 & 88 & 0.0000 \\
Observation chart & 87 & 99 & 0.0000 \\
Newborn notes & 50 & 97 & 0.8 \\
Postnatal cards & 94 & 96 & 0.0000 \\
Antenatal notes & 43 & & \\
\hline
\end{tabular}

\section{DISCUSSION}

The study showed a good record retrieval rate of $87 \%$ in the group before the SMDP and 90\% in the group during the implementation of SMDP. The demographic data, taken in the admission room for all patients due for admission by the nurse on duty, were well recorded before $(\geq 96 \%)$ and during the SMDP implementation ( $299 \%$ ) except religion which was poorly recorded in both groups. This may be attributed to the fact that religion is hardly over referred to in management of labour or administratively.
History taking plays an important role in making a diagnosis and plan of management in the intrapartum period. Main complaints, history of present illness and past medical history were equally well recorded in $95 \%$ and over of the records during both periods of study. Recording of family and social history, marital status, employment, chronic illness in the family and history of twin pregnancy was greatly improved during the SMDP implementation $(99 \%-100 \%)$ compared to before SMDP (83\% - 90\%). 
The recording of menarche, history of previous pregnancy and contraceptive use remained at a low level during the SMDP. Menarche and characteristics of menstrual period help to ascertain the last normal menstrual period. Knowledge of contraceptive use helps ascertain the character of menstrual flow prior to conception while history of previous pregnancies is important in the management of intrapartum period. In this study, these parameters were poorly recorded before the SMDP ( $42 \%$ and $45 \%$ respectively) with no appreciable improvement during the SMDP ( $47 \%$ and $50 \%$ respectively). In comparison with an audit of care given to mothers in a maternity unit in a large academic hospital, Maclnemney et al (17) found that past medical history was documented in only $54 \%$ of the cases admitted. Antenatal clinic records in PGHK improved from $88 \%$ in the first group to $90 \%$ in the second group. This was much better than in the Macinerney audit where present antenatal history was reflected in only $12.2 \%$ of the records (7).

General and obstetric examinations were well documented before SMDP (91\%-100\%) and during the SMDP $(100 \%)$. There was an improvement in documentation of diagnosis and plan of management from about $88 \%$ and $84 \%$ respectively before SMDP to $100 \%$ and $96 \%$ respectively, during the SMDP.

The most important document in the intrapartum period is the partograph. It is only useful if well documented and timely action is taken (10-14). Despite the ample demonstration by WHO of the superiority of a partograph as an intrapartum monitoring tool, it has only ben extensively used in a few countries (12). In this study the partograph was used only in $11 \%$ of the patients in the first group compared to $85 \%$ in the second group. The SMDP mostly targeted the intrapartum period and there was a great impact. It must be noted that most of the mothers managed by partograph in the first group were study cases by student midwives from the Kenya Medical Training Centre Kakamega. It was therefore not routine to complete a partograph in Kakamega before the introduction of SMDP.

For the purposes of comparing the appropriateness of use of partograph, the 22 cases in which a partograph was used in the first group were compared with 171 cases in the second group where the partograph was used. It is appreciated that study patients by student nurses could bias the results and may not accurately reflect the standard practice of record keeping in the intrapartum period in the hospital.

All parameters on the foetal condition and progress of labour in the group during the SMDP implementation were documented. In the group before SMDP, status of membranes, cervical dilatation and descent of presenting part were recorded in 20 out of 22 partographs (91\%). In a set up where monitoring of labour by partograph was not routine it is commendable that only 2 out of 22 partographs mostly filled by student midwives failed to record parameters on foetal condition. During the SMDP on the other hand, the importance of monitoring the foetal condition was fully appreciated and its parameters recorded. However, the data only reflects recording of the parameters without mention of the frequency with which they were observed and recorded i.e. half hourly for foetal heart rate and status of membranes and liquor amnii and every four hourly for the others, during the active phase of labour.

Appreciation of moulding, caput formation and significance of a crossed alert line and more so the action line is the hallmark in the diagnosis of abnormnal progress of labour long before it becomes prolonged and obstructed (1). In this study, on average, $23 \%$ of the partographs both before and during SMDP had no record of degree of moulding and caput formation. This is an area that needs to be revisited both in the KMTC Kakamega and continuous medical education among trained staff in PGH Kakamega. This compares with Macinerney's study where only $18 \%$ of the records had complete vaginal examination findings.

In Njoroge's study carried out at a rural district in Kenya, $50 \%$ of the health care workers had low knowledge of the partograph (14). The study also showed that the ability to use parameters on the partograph to make decisions was low and of the respondents, $60 \%$ could not apply the findings on the partograph to make a decision on active management of labour.

Monitoring the maternal condition is one of the major components in management of labour. Blood pressure measurement helps in diagnosing and monitoring such conditions as preeclampsia /eclampsia and shock while, monitoring of pulse, respiration rate and temperature helps in assessing the general condition of the patient. There was marked improvement in monitoring and recording 
of all these parameters during the SMDP. $A$ t the same time the recording of urinalysis and monitoring for ketonuria, and proteinuria, being the quickes means of assessing renal functions, which are adversely affected in such conditions as PET/Eclampsia, shock, and diabetic ketoacidosis improved moderately duritig the SMDP?

Summary of laboun was generally well documented in both groups, the difference being, that the majority of labour summaries in the group before SMDP were not recorded on a partograph, which was used in only $11 \%$ of the cases. Apart from the partograph the data was sourced from admission notes, intrapartum case notes and discharge summaries. A general improvement in recording summary of labour was noted during the SMDP. The most significant improvement was blood pressure assessment during SMDP. Comprehensiveness of record storage was greatly improved during the SMDP, notably the treatment sheet which was retrieved in $48 \%$ of cases in first group compared to $88 \%$ of cases in second group. Likewise new born notes and antenatal notes were retrieved in $50 \%$ and $43 \%$ respectively before the SMDP as compared to about $97 \%$ and $96 \%$ respectively during the SMDP.

\section{CONCLUSION}

The quality of records in the intrapartum period at the PGH Kakamega before the introduction of SMDP was poor, especially the dismal use of partograph. With the introduction of SMDP the record keeping drastically improved and the partograph was incorporated in the management of labour. Continuous medical education and seminars for all medical personnel through such projects as SMDP should be extended across the country to revive and sustain good obstetric care and recording during labour and delivery through appropriate partograph use among other measures. Sustained provision of stationery and supervision by managers would ensure uninterrupted record keeping in health delivery centers.

\section{ACKNOWLEDGEMENT}

To the Ministry of Health PMOs office, the staff of Provincial General Hospital, Kakamega, The Population Council, Nairobi the administrator of the SMDP and Department for International Development (DFiD) for providing the funding for the SMDP.

\section{REFERENCES}

1. WHO. Maternal Health and Safe Motherhood Program preventing prolonged labour. A practical guide. The partography part 1. 199.

2. WHO. Application of the WHO partograph in the management of labour: Report of a WHO multi centre study 1990-1991. WHO/FHE/MSM/94.4.

3. WHO. Preventing prolonged labour. A practical guide. The partograph part 2, $3 \&$ 4. WHO/FHE/MSM/93.8.

4. Wasike C.S.G. Evaluation of the impact of the Ministry of Health partograph on active management of labour at Moi Teaching and Referral Hospital Eldoret. M.Med. Thesis University of Nairobi, 1999.

5. Wanjara M.J. The management of labour using partographs in a rural hospital in Kenya. MMed Thesis, University of Nairobi, 1991.

6. Ministry of Health, Population Council and University of Nairobi. Safe Motherhood Project -A demonstration project on approaches to providing quality maternal care in Kenya. Preliminary findings from the baseline survey of December 2000. Draft of May 2001.

7. Mcelnerney P.A., Lester B. and Rapetswa L. An Audit of care given to mothers in a maternity unit of a large academic hospital. AJNM. 2000; 21: 35-38.

8. Ministry of Health. Health Information Systems. Demographic data for women within reproductive age (15-49 years) 2001.

9. Hendricks C.H., Brener W.E. and Krausa, Normal cervical dilatation pattern in late pregnancy and labour. Amer J.Obs. Gynae. 1970; 106: 1065-1082.

10. Philpot R.H. and Castle W.M. Cervicographs in the management of labour in primigravidae $I$. The alert line for detecting of abnormal labour. J. Obs. Gynae. Brit. Commonwealth. 1972; 79: 592-598.

11. Philpot R.H. and Castle W.M. Cervicographs in the management of labour in primigravidae 11. The action line and treatment of abnormal labour. 1. Obs. Gynae. Brit. Commonwealth. 1972; 79: 599-602.

12. Philpot R.H. Graphic records in labour. Brit.Med. J. 1972; 4: 163-165.

13. Sungani F.C.M. Partographs in management of labour in primnividae in Kenyatta National Hospital. MMed Thesis, University of Nairobi. 1979.

14. Njoroge G.W. A survey to determine knowledge Attitude and Practices related to the use of partographs among medical personnel involved in management of labour in a rural district in Kenya. MMed Thesis, University of Nairobi. 1993.

15. Mati J.K.G., Aggarwal V.P., Lucas S., et al. The Nairobi Birth Survey III. Labour and delivery. T. Obstet. Gymaecol. E. \& C. Afr. 1983; 2: 56-61. 